\title{
表面化学反応の実時間・実空間分解分光への挑戦： 不可逆かつ不均一な反応の追跡を目指して
}

\author{
雨 宮 健 太 \\ 高エネルギー加速器研究機構物質構造科学研究所＼cjkstart函305-0801＼cjkstart茨城県つくば市大穗 1-1
}

（2015 年 1 月 19 日受付；2015 年 2 月 27 日掲載決定）

\begin{abstract}
Challenge for Real-Time and Real-Space Resolved Spectroscopy of Surface Chemical Reactions : Aiming at Trace of Irreversible and Inhomogeneous Reactions
\end{abstract}

Kenta AmemiYa

High Energy Accelerator Research Organization, 1-1 Oho, Tsukuba, Ibaraki 305-0801

(Received January 19, 2015 ; Accepted February 27, 2015)

\begin{abstract}
A novel experimental technique, time-resolved wavelength-dispersive soft X-ray imaging spectroscopy, is proposed in order to achieve real-time and real-space resolved spectroscopy for the observation of irreversible and inhomogeneous surface chemical reactions. By combining the wavelength-dispersed soft X rays, in which the X-ray wavelength (photon energy) changes as a function of position on the sample, with the photoelectron emission microscope, the soft X-ray absorption spectra are separately obtained at different positions on the sample without scanning the X-ray monochromator. Therefore, the real-time resolved measurement of site-selective soft X-ray absorption spectroscopy is realized in one event without repeating the chemical reaction. It is expected that the spatial distribution of different chemical species is traced during the surface chemical reaction, which is essential to understand the reaction mechanism.
\end{abstract}

KEYWORDS : surface chemical reaction, real-time resolved, real-space resolved, irreversible, inhomogeneous

\section{1. は じめに}

表面化学反応の進行中において，様々な化学種が時々 刻々と変化していく様子を定量的に追跡することは，反 応の機構を理解し, 設計するための第一歩である。時間 分解測定には通常, いわゆるポンププローブ法, すなわ ちイベントを開始させる（ポンプする）タイミングと観 察する（プローブする）タイミングを少しずつ変えなが ら何千, 何万回とイベントを繰り返す手法が, しばしば 用いられる。ところが表面化学反応は多くの場合, 頻繁 な繰り返しが困難なため, このようなポンププローブ法 による時間分解測定法の適用が難しい。つまり, 時間分 解測定の立場からは, 表面化学反応は実質的に不可逆な ものと考える必要があり, そうした不可逆な反応を，一 度のイベントの間に追跡できる, 実時間分解測定法の開

E-mail : kenta.amemiya@kek.jp

\section{発が重要である。}

筆者らは 10 年来, 波長分散した（位置によって波長 の異なる) 軟 X 線を試料に照射し, それぞれの位置 （波長に対応する）において軟 X 線の吸収量に比例して 放出される Auger 電子を, 位置分解して同時に取り达む ことによって, 軟 X 線分光器を掃引することなく軟 X 線吸収スペクトルを得る手法（波長分散型 X 線吸収分 光法）を開発しており ${ }^{1 \sim 3)}$, 最近では $33 \mathrm{~ms}$ 間隔でスぺ クトルを連続测定することに成功した ${ }^{3)}$ 。この手法で は, 試料表面において水平方向に数 $\mathrm{mm}$ 程度の範囲で 軟 $\mathrm{X}$ 線のエネルギーが $20 \mathrm{eV}$ 程度変化する一方, 垂直 方向には $0.2 \sim 0.5 \mathrm{~mm}$ 程度の幅をもったビームを照射し ている。すなわち, $\mathrm{mm}$ 程度の範囲における化学種の量 を平均化したものを, 実時間で追跡するものである。

もちろん，このような空間的に平均化したキネティク スの情報はきわめて重要であるが, 表面化学反応はしば しば, マイクロメーター, ナノメーターといったスケー 
ルで見ると不均一に進行しており，こうした反応を正し く理解するには, 時間分解能だけでなく空間分解能をも 同時に有する測定手法が必要である。本稿では, 不可逆 （一度しか扔きない）かつ不均一な表面化学反応を，実 時間（繰り返しに頼らず）かつ穾空間（イメージング） で分光学的に追跡するという，一見不可能に思える測定 手法を実現するにはどうしたらよいか，予備的な実験デ ータを交えながら検討したい。

\section{2. 波長分散型イメージング分光法}

\section{1 コンセプトとシミュレーション}

Fig. 1 に波長分散型イメージング分光法のコンセプト を示す。まず，白色軟 X 線を回折格子に照射すること によって, 出射スリット位置において波長分散した軟 X 線が得られる。これを集光鏡によって試料位置に導くこ とによって, Fig. 1 に示すように試料位置において一方 向（ここでは図の上下方向）に波長分散した軟 X 線を 試料に照射することができる。したがって, 試料表面に 存在する分子や原子には，それぞれの位置に対応した波 長 (エネルギー) の軟 X 線が照射されることになる。 すなわち，試料上に打ける波長分散方向の位置が，X線 吸収分光法に扔けるエネルギー軸に対応する。分子や原 子が軟 X 線を吸収すると, 内殼に空孔が生じ，その空 孔の緩和過程において Auger 電子が放出されるので, そ れぞれの位置から放出される Auger 電子の数は, その位 置に対応したエネルギーをもつ軟 X 線の吸収量に比例 する。従来の波長分散型 X 線吸収分光法では, ここで 波長分散方向に一次元イメージング機能を有する電子分 光器を用いて Auger 電子を位置分解して取り达み, Auger 電子の強度を位置に対してプロットすることによ って軟 X 線吸収スペクトルを得るのであるが，ここで は放出電子の二次元イメージングができる光電子顕微鏡 (Photoelectron emission microscope ; PEEM) を用いて電 子を取り达む。すると, 得られる二次元電子像のうち, 図の左右（X）方向はそのまま位置情報になるが，上下

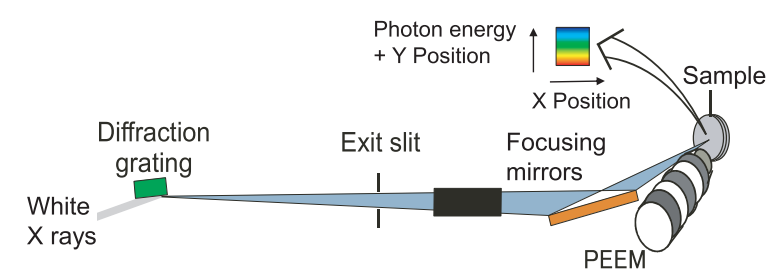

Fig. 1. (color online). Basic concept for the wavelengthdispersive soft X-ray imaging spectroscopy. Wavelengthdispersed $\mathrm{X}$ rays illuminate the sample surface, and the emitted electrons are collected by a photoelectron emission microscope (PEEM).
（Y）方向は位置情報と軟 X 線の波長（エネルギー）情 報の両方を含むことになる。

残念ながらこの手法では，ある位置にはある特定の波 長の軟 X 線しか照射されないので，すべての位置にお ける軟 X 線吸収スペクトルを完全に独立に得ることは 原理的に不可能である。しかしながら，たとえば化学反 応中の表面に押いて，本質的には同等と見なせるたくさ んのアイランドが空間的に分布している場合を考える と, アイランドの中と外, 場合によってはアイランドの 縁，といった部分に対する軟 X 線吸収スペクトルを 別々に得ることは可能である。Fig. 2にこのような例に ついてのシミュレーションを示す。

まず, Fig. 2 (a) のように，化学反応中のある瞬間の 表面にたくさんのアイランドが存在すると仮定する。解 析に扔いて，このアイランドがどのような化学種からな るかを先に知っておく必要はないが，ここではシミュレ ーションのためにアイランドの中は原子状の酸素 (O), 外側は分子上の CO で覆われていると仮定する。また, $\mathrm{O}$ と $\mathrm{CO}$ それぞれに対する酸素 $\mathrm{K}$ 吸収端の軟 $\mathrm{X}$ 線吸収 スペクトルは Fig. 2（b）のようになっているとする。 この表面に図で左右方向に波長分散した軟 X 線を照射 する。ここでは, 酸素の $\mathrm{K}$ 吸収端付近 $(525 \sim 545 \mathrm{eV}$ の 範囲）の軟 X 線を想定している。すると, 表面上のそ れぞれの位置では, そこに存在する化学種と, その位置 での軟 X 線エネルギーに応じて軟 X 線の吸収が起こり, その吸収量に比例した Auger 電子が放出される。この様 子をシミュレートしたのが Fig. 2 (c) である。たとえ ばアイランドの中は原子状 $\mathrm{O}$ からなるので, $532 \mathrm{eV}$ 付 近で最も強い吸収が起こり, それを反映してこのエネル ギーに対応する位置（X=35 $\mu \mathrm{m}$ 付近）ではアイランド が明るく見えている。一方 $\mathrm{CO}$ は $535 \mathrm{eV}$ 付近に吸収の ピークをもつため, アイランドの外側の部分は X=50 $\mu \mathrm{m}$ 付近で明るい带となっている。最後にこうした Auger 電子の放出強度を, 軟 $\mathrm{X}$ 線エネルギーの関数とし てプロットしたのが Fig. 2 (d) である。ただしこの際 に，アイランドの中と外とで別々に強度を足し算してい る。このようにして，アイランドの中と外に対して得ら れたスペクトルは，それぞれOと CO のスペクトルを 再現しており，アイランドの内外のスペクトルを正しく 分離できていることがわかる。なお，ここではアイラン ドの中が $\mathrm{O}$ ，外が $\mathrm{CO}$ という単純な場合を示したが，た とえばアイランドの中は O が $70 \%$ で CO が 30\%，外は O が $15 \%$ で CO が $85 \%$ といった状態であれば，同様な 操作によって得られるスペクトルは，これらの比率を反 映した重ねあわせになり，標準スペクトル等を用いるこ とで, アイランドの内外における化学種の量を正しく評 
(a)

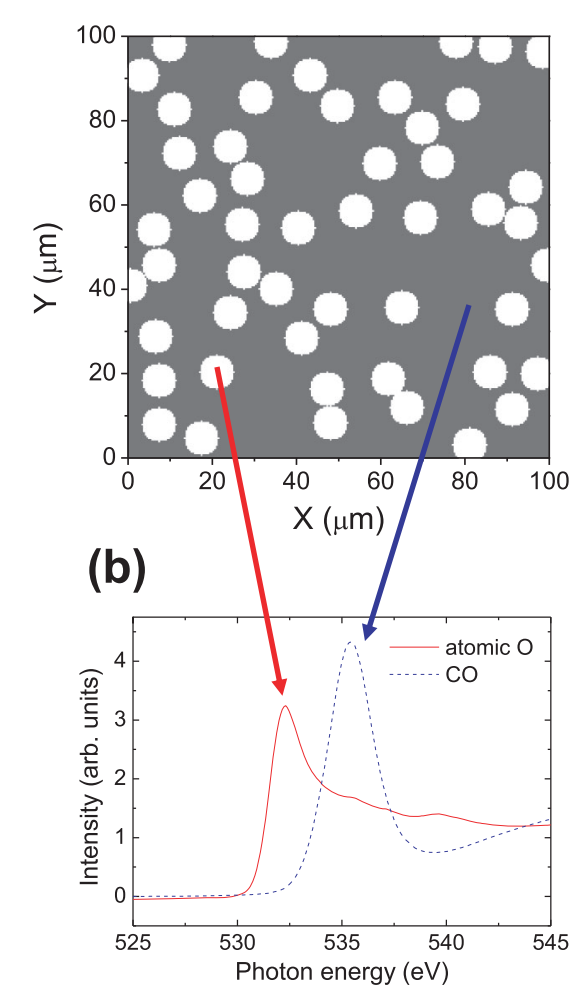

(c)

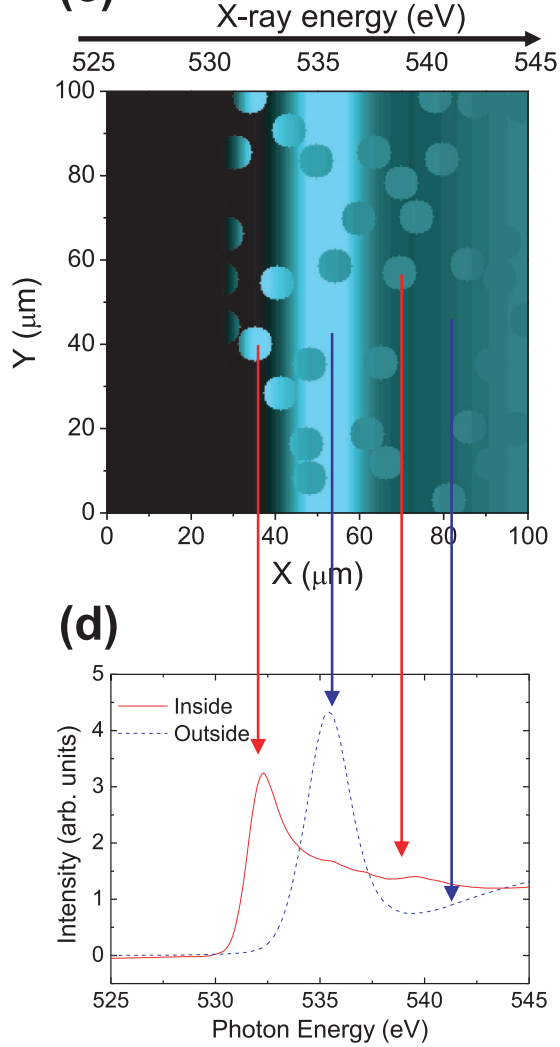

Fig. 2. (color online). Simulation for the wavelength-dispersive soft X-ray imaging spectroscopy. It is assumed that atomic oxygen forms islands as illustrated in (a) by white circles, which are surrounded by molecular $\mathrm{CO}$, and that atomic $\mathrm{O}$ and molecular $\mathrm{CO}$ exhibit the X-ray absorption spectra shown in (b). When the wavelength-dispersed X rays, whose photon energy changes along the horizontal axis, illuminate the surface, the Auger electrons are emitted from each position according to the absorption intensity at the corresponding photon energy as illustrated in (c). The X-ray absorption spectra for inside and outside of the islands are obtained by separately summing the Auger electron intensity for inside and outside of the islands as a function of photon energy as shown in (d).

価できる。

ただし，この手法が本当にうまくいくかどうかを考え ると，いくつもの不安な点があげられる。まず，ある位 置にあるアイランドと別の位置のアイランドが本当に同 等かという問題である。少なくとも，それぞれのアイラ ンドに含まれる化学種の量や比率が互いに等しい必要が ある。また, アイランドなどの空間的な構造が, あまり にもまばらだと, あるエネルギーではアイランドが一つ もない, などということが起こってしまう。これらの問 題はケースバイケースといわざるを得ない。

一方, 解析上の問題の一つとして, 空間的な構造, た とえばアイランドの中と外をどうやって見分けるのかと いう点は重要である。Fig. 2(c) を見ると, $535 \mathrm{eV}$ に対 応するあたりはコントラストが高いので見分けるのは簡 単だが, $540 \mathrm{eV}$ 以上になるとかなり難しくなる。もっ ともこれは, アイランドの内外で吸収強度にあまり差が
ないためなので, もしも間違えてカウントしても, 得ら れるスペクトルに大きな変化はないという考え方もでき る。もっと本質的には，たとえば波長分散した軟 X 線 と単色の真空紫外光を交互に照射し, 真空紫外光を用い てそれぞれの瞬間のアイランドの位置を決めた上で軟 X 線のデー夕を解析するという解決策も考えられる。

さらに, 軟 X線強度のエネルギー依存性や, 検出器 の不均一性が問題になるのではないか, という不安もあ る。ただ，これに関しては従来の波長分散型 X 線吸収 分光法と同様に解決できると考えられる。すなわち, 試 料が測定対象の元素を含まない状態（たとえば化学反応 にかかわる吸着種が表面にない状態）では, 軟 X 線の 吸収確率は軟 X 線のエネルギーにほとんど依存しない ため, 放出される Auger 電子の数は, それぞれの位置に おける軟 X 線の強度と検出器の感度の積に比例する。 この状態でデー夕を測定しておいて, 実際の反応中のデ 


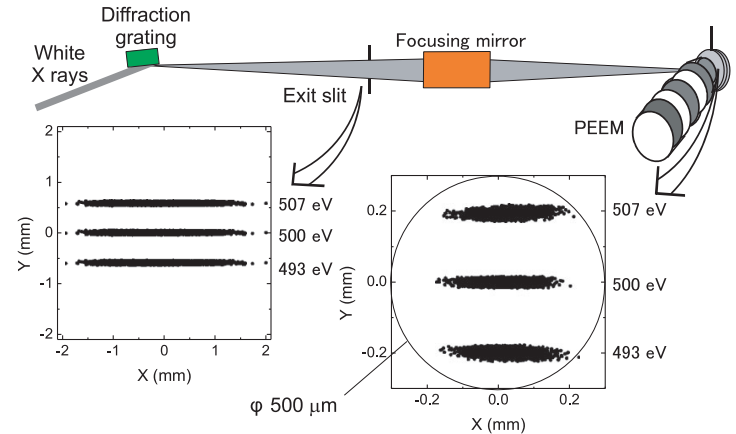

Fig. 3. (color online). Schematic layout for the optics to obtain wavelength-dispersed soft $\mathrm{X}$ rays at the sample position. The ray-tracing results at the exit slit and sample positions are also shown.

ータに対して割り算を行うことによって, 軟 X 線強度 のエネルギー依存性と検出器の不均一性を, まとめて補 正することができる。

\section{2 光学系の設計}

ここで検討している波長分散型イメージング分光法を 実現するには，試料表面に波長分散した軟 X 線を照射 することが重要なポイントの一つである。これ自体は, 従来の波長分散型軟 X 線吸収分光法で実現しているが, 空間分解能をもたせようとしたときに, 広い視野で高い 空間分解能を実現するのは一般に難しいので，比較的狭 い領域に波長分散した軟 X 線を押し込める必要がある。 そこでここでは, 直径 $500 \mu \mathrm{m}$ の視野を想定して光学系 の設計を行う。通常, 視野の $1 / 1000$ 程度の空間分解能 は実現できると考えられるので，これは空間分解能 500 $\mathrm{nm}$ 程度に対応する。

Fig. 3 に光学系の例と, 得られる軟 X 線の空間分布を 示す。出射スリットまでの光学系は, 高エネルギー加速 器研究機構放射光科学研究施設のアンジュレータビーム ライン BL-16A ${ }^{4)}$ をそのまま用いている。ただし，直径 $500 \mu \mathrm{m}$ の領域に, それなりのエネルギー範囲で波長分 散した軟 X 線を照射するためには，回折格子の刻線密 度を低くするか, 集光光学系の縮小率を上げる必要があ り，ここでは $1 \mathrm{~mm}$ あたり 150 本の回折格子を採用して いる。図に示すように，出射スリット位置において 1 $\mathrm{mm}$ 程度の範囲に $15 \mathrm{eV}$ 程度の範囲で波長分散した軟 $\mathrm{X}$ 線が得られ，それを縮小率 $3: 1$ の集光光学系で再集光 することによって，試料位置では直径 $500 \mu \mathrm{m}$ の中に 15 $\mathrm{eV}$ 程度の波長分散となる。

\section{3 予備的な実験結果}

最後に，きわめて予備的な実験結果として, Fig. 3 と は異なる光学系ではあるが，試料に波長分散した軟 X 線を照射し，PEEM を用いて放出される電子を二次元位

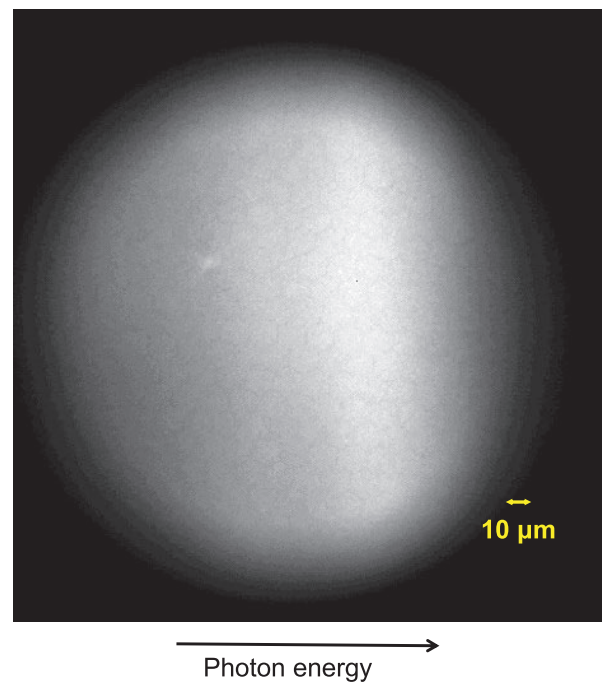

Fig. 4. (color online). Spatial distribution of electrons emitted from a $\mathrm{Ni}$ thin film illuminated by wavelengthdispersed $\mathrm{X}$ rays around the Ni L edge.

置分解して検出した結果を Fig. 4 に示す。試料は $\mathrm{Cu}$ 上 に成長させた Ni 薄膜で, Ni の L3 吸収端 $(852 \mathrm{eV})$ 付 近で $15 \mathrm{eV}$ 程度の範囲で波長分散した軟 $\mathrm{X}$ 線を照射し ている。集光光学系の調整が不十分なために像がぼやけ ているが，中央よりやや右側に，Niの吸収ピークに対 応する明るい帯が見えている。このようなデー夕は CCD カメラによって連続的に測定できるので，繰り返 しによらずに時間分解測定を行うことが可能である。

\section{3. を め}

波長分散した軟 X 線を試料表面に照射し，放出され る Auger 電子を光電子顕微鏡を用いて二次元位置分解し て取り込むことによって，不可逆かつ不均一に進行する 表面化学反応を, 実時間, 実空間分解しながら分光学的 に追跡できる可能性を示した。今後，光学系の整備を進 め, 原理の検証および実際の表面化学反応の追跡を行う 予定である。

\section{文献}

1) K. Amemiya, H. Kondoh, T. Yokoyama and T. Ohta : Jpn. J. Appl. Phys. 40, L718 (2001)

2) 雨宮健太 : 放射光 25, 269 (2012).

3) K. Amemiya, Y. Kousa, S. Nakamoto, T. Harada, S. Kozai, M. Yoshida, H. Abe, R. Sumii, M. Sakamaki and H. Kondoh : Appl. Phys. Lett. 99, 074104 (2011).

4) K. Amemiya, A. Toyoshima, T. Kikuchi, T. Kosuge, K. Nigorikawa, R. Sumii and K. Ito : AIP Conf. Proc. 1234, 295 (2010). 